Int. J. Electrochem. Sci., 11 (2016) 2971 - 2981

International Journal of

ELECTROCHEMICAL

SCIENCE

www.electrochemsci.org

\title{
Highly Sensitive Determination of Caffeic Acid Using a Multi- walled Carbon Nanotubes Modified Electrode with N- Butylpyridinium Hexafluorophosphate Ionic Liquid and Chitosan as Binders
}

\author{
Hongjiao Zhang ${ }^{1,2}$, Yuntao Gao ${ }^{1,2, *}$, Huabin Xiong ${ }^{1,2}$, Xiaofen Li $^{1,2}$, Sifeng Zhang ${ }^{1,2}$, \\ Bowen Shi ${ }^{1,2}$, Limei Duan ${ }^{1,2}$ \\ ${ }^{1}$ Key Laboratory of Comprehensive Utilization of Mineral Resources in Ethnic Regions, Yunnan \\ Minzu University, Kunming 650500, PR China \\ ${ }^{2}$ Joint Research Centre for International Cross-border Ethnic Regions Biomass Clean Utilization in \\ Yunnan, Yunnan Minzu University, Kunming 650500, PR China \\ *E-mail: ymz409@163.com
}

doi: $10.20964 / 110402971$

Received: 21 January 2016 / Accepted: 10 February 2016 / Published: 1 March 2016

\begin{abstract}
Multi-walled carbon nanotubes-N-Butylpyridinium hexafluorophosphate ionic liquid-chitosan composite film modified glassy carbon electrode (MWNTs-[BuPy]PF 6 -CS/GCE) was prepared and it was applied to the quantitative analysis of caffeic acid. A pair of redox peak with a well-defined electrochemical response signal of caffeic acid was obtained by using cyclic voltammetry $(\mathrm{CV})$ in 0.04 $\mathrm{mol} \cdot \mathrm{L}^{-1} \mathrm{BR}$ buffer solution ( $\mathrm{pH} 4.0$ ). A novel electrochemical method to determine the caffeic acid with differential pulse voltammetry (DPV) was developed based on the MWNTs-[BuPy]PF ${ }_{6}-\mathrm{CS}_{\mathrm{GCE}}$. The DPV oxidation peak current showed a good linear relationship with the concentration of caffeic acid in the range from $2.5 \times 10^{-8}$ to $7.0 \times 10^{-6} \mathrm{~mol} \cdot \mathrm{L}^{-1}$ and the detection limit can reach $5.7 \times 10^{-9} \mathrm{~mol} \cdot \mathrm{L}^{-1}$. The proposed method can be used for the determination of caffeic acid with the recovery of 96.9$102.8 \%$ and the RSD of $2.2-3.1 \%$ in real sample.
\end{abstract}

Keywords: Caffeic acid; Multi-walled carbon nanotubes; Ionic liquid; N-Butylpyridinium hexafluorophosphate; Chitosan.

\section{$\underline{\text { FULL TEXT }}$}

(C) 2016 The Authors. Published by ESG (www.electrochemsci.org). This article is an open access article distributed under the terms and conditions of the Creative Commons Attribution license (http://creativecommons.org/licenses/by/4.0/). 